\title{
Produção científica da Sociedade Brasileira de Pneumologia e Tisiologia: 1979 a 2006
}

\author{
Scientific production of the Brazilian Society of Pulmonology and \\ Phthisiology: 1979-2006
}

\author{
ANA MARIA BAPTISTA MENEZES
}

Em um levantamento realizado em 1969, as pesquisas sobre "Biologia e Ciências Médicas" correspondiam a um terço de todos os projetos em andamento, ocupando a posição de líder com 926 projetos. Seguiam-se a Agricultura (674 projetos), Ciências Sociais (349), Tecnologia (234), Ciências da Terra (190) e Química (152). Com relação aos auxilios financeiros concedidos para o desenvolvimento dessas pesquisas, entretanto, a parcela da área da saúde era, relativamente, bem mais modesta do que as das demais áreas. ${ }^{(1)}$

Após três décadas, as Ciências Biológicas e da Saúde permanecem responsáveis pelo maior número de linhas de pesquisa (21.371), correspondendo a 30\% do total das grandes áreas do conhecimento, segundo o Conselho Nacional de Pesquisa e Desenvolvimento (CNPq). Desde 1969, houve um significativo aumento do fomento à pesquisa para as Ciências Biológicas e da Saúde oriundo do CNPq, o qual atingiu o percentual de $30 \%$ no ano de 2004. ${ }^{(2)}$

Linhas de pesquisa e fomento à pesquisa são o alicerce para a produção científica, sob a forma de publicações, livros, apresentações em congressos ou relatórios técnicos. Estes, por sua vez, revelam o avanço do conhecimento científico, fenômeno que vem sendo demonstrado nas mais diversas áreas do conhecimento. Dentro da área da saúde, a Pneumologia vem acompanhando esse crescimento e cada vez mais contribui para o "estado da arte" da sua especialidade, com progressivo aumento do número de apresentações em congressos e publicações, tema abordado neste volume do Jornal Brasileiro de Pneumologia (JBP), no artigo intitulado: "Perfil da atividade de pesquisa publicada nos anais dos congressos brasileiros de Pneumologia e Tisiologia nos últimos vinte anos", de Fabro, Yoo e Queluz. ${ }^{(3)}$ Sabe-se, porém, que as publicações em revistas e jornais são, atualmente, a principal forma de propagação do conhecimento e do reconhecimento da ciência em nível mundial.

A inserção do pneumologista na pesquisa científica é o que the assegura a possibilidade de participar do cenário mundial da ciência, testando novas hipóteses, identificando prioridades em saúde ou recomendando condutas diagnósticas e terapêuticas.

Com o intuito de avaliar a tendência temporal da pesquisa, na área da Pneumologia do país, realizou-se uma busca bibliográfica por nomes de autores (pneumologistas membros da Sociedade Brasileira de Pneumologia e Tisiologia - SBPT), de 1979 a 2006, em duas das maiores bases de dados de publicações internacionais e da América Latina: MEDLINE e LILACS. Não se pretendeu com esta pesquisa abranger toda a Pneumologia brasileira, pois se sabe que há pneumologistas que não pertencem ao quadro de sócios da SBPT, assim como há publicações na área da Pneumologia de autores não sócios da SBPT. Acredita-se, contudo, que uma busca de cerca de 2.400 nomes pertencentes à SBPT reflita de uma maneira global a produção científica da área no país e internacionalmente. Para não haver duplicação na busca e para restringi-la apenas à área da Pneumologia, adotaram-se algumas estratégias: publicações encontradas nas duas bases de dados pesquisadas foram incluídas apenas no MEDLINE, já que as revistas indexadas nesta base de dados têm maior índice de impacto do que aquelas encontradas na LILACS; publicações de vários autores sócios da SBPT contaram apenas como uma publicação em nome do primeiro autor; publicações de autores sócios da SBPT, mas não referentes à área de Pneumologia, foram excluídas dos resultados; as instituições de origem consideradas foram aquelas do primeiro autor do manuscrito.

Somente publicações de artigos foram incluídas na pesquisa, sendo excluídas teses, capítulos de livros, livros ou textos técnicos. Um total de 1.502 publicações foi identificado, sendo 752 da 
MEDLINE e 750 da LILACS. 0 número de publicações conforme o ano (Figura 1) revela um acréscimo de cerca de 80 vezes no número das publicações de 1979 para 2005, comparado a duas vezes mais no número de publicações de resumos nos Anais dos Congressos Brasileiros de Pneumologia e Tisiologia no período de 1986 a 2004, citado no artigo de Yoo, Fabro e Queluz. ${ }^{(3)}$

Com relação às revistas mais freqüentemente utilizadas para estas publicações, encontra-se o JBP (J Bras Pneumol - outrora Jornal de Pneumologia) com o maior percentual de publicações, $23,2 \%$, seguido de percentuais de 3,3\% até 1,2\% para as outras revistas da área (Figura 2). Revistas internacionais de maior impacto como o Chest, European Respiratory Journal (ERJ) e American Journal of Respiratory and Critical Care Medicine (AJRCCM) ocuparam o $3^{\circ}, 4^{\circ}$ e $6^{\circ}$ lugares, respectivamente. Na mesma posição do ERJ encontram-se o Jornal de Pediatria e o Pulmão (Rio de Janeiro), e na do MJRCC está o Brazilian Journal of Medical and Biological Research (Braz J Med Biol Res).

Assim como foi observado por Fabro, Yoo e Queluz, em relação aos resumos de congressos, a Região Sudeste destaca-se pelo maior número de publicações científicas na área da Pneumologia. Cabe ressaltar que os quatro primeiros Estados no ranking da produção de artigos científicos, São Paulo (38,5\%), Rio de Janeiro (16,7\%), Rio Grande do Sul $(13,2 \%)$ e Minas Gerais (4,2\%), também são os com o maior percentual de sócios dentro da SBPT. Nota-se, contudo, que o percentual de

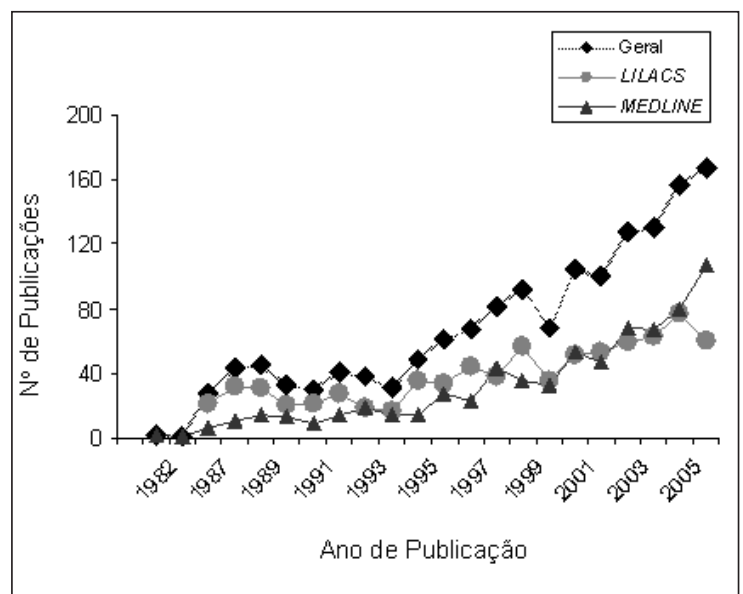

Figura 1 - Tendência temporal das publicações da SBPT: $1979-2005$

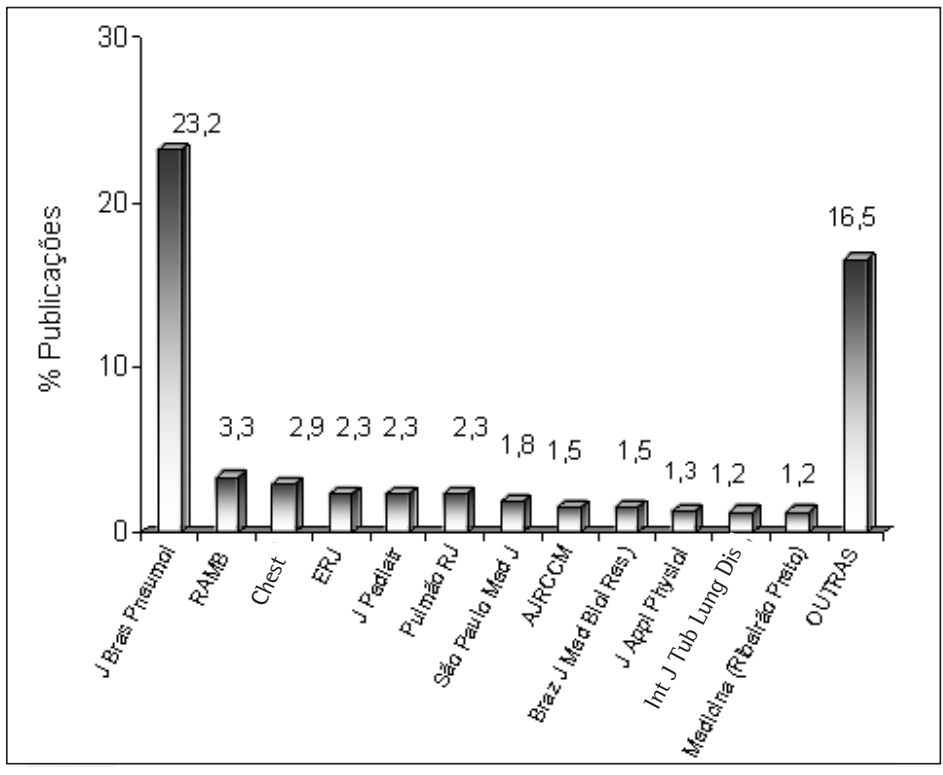

Figura 2 - Publicações da SBPT conforme as revistas:1979 - 2006

sócios da SBPT das unidades de Minas Gerais e do Rio Grande do Sul é quase o mesmo: 10\% e 9,6\%, respectivamente (Figura 3).

Em um país ainda em desenvolvimento como o Brasil, com uma política pouco voltada para a educação, ciência e pesquisa, é preciso muita determinação, espírito inovador e ambição científica, em detrimento muitas vezes da financeira, para acompanhar o avanço do conhecimento no restante do mundo, hoje globalizado. A produção científica da SBPT, sem dúvida, tem mostrado um

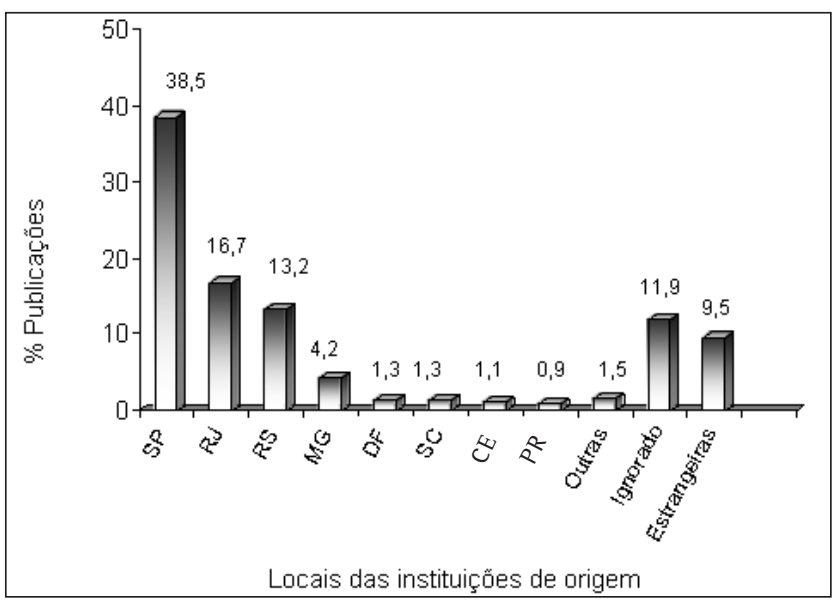

Figura 3 - Publicações da SBPT conforme os locais das instituições: $1979-2006$ 
importante crescimento nos últimos 26 anos. É preciso que este crescimento aconteça não apenas em número, mas em qualidade. Ainda publicamos pouco em revistas internacionais e de grande impacto, sendo o Jornal Brasileiro de Pneumologia o local onde estão publicadas um quarto das pesquisas da SBPT. Deve ser prioridade da SBPT conduzir o Jornal Brasileiro de Pneumologia ao mais elevado nível científico dentro da literatura médica. A indexação de uma revista no MEDLINE, atualmente, ainda é o fator dominante para o índice de impacto da mesma.

A nós, pneumologistas da SBPT, cabe a responsabilidade, perante a comunidade científica e leiga, pela disseminação do conhecimento livre de quaisquer influências que não sejam apenas os princípios éticos da pesquisa em saúde.
ANA MARIA BAPTISTA MENEZES

Professora Titular de Pneumologia da Universidade Federal de Pelotas - UFPEL; Coordenadora do Programa de Pós-Graduação em Epidemiologia da UFPEL Pelotas (RS) Brasil.

\section{REFERÊNCIAS}

1. Rigatto M. Pesquisa médica: retrospecção e prospecção. In: Rigatto M. Médicos e Sociedade. Porto Alegre: Livraria da Globo: 1976. (Fundo Editorial Byk-Procienx)

2. Brasil. Conselho Nacional do Desenvolvimento Cientifico e Tecnológico. Estatísticas e Indicadores de Fomento do CNPq [texto na Internet]. Brasília: CNPq. [citado 2006 Nov 11]. Disponível em: http:// www.cnpq.br/estatísticas/estat_ind_fom.htm.

3. Fabro AT, Yoo HHB, Queluz TT. Perfil da atividade de pesquisa publicada nos anais dos congressos brasileiros de pneumologia e tisiologia nos últimos 20 anos. J Bras Pneumol. 2006;32(4)309-15. 